\title{
Differential Control of Synaptic and Ectopic Vesicular Release of Glutamate
}

\author{
Ko Matsui and Craig E. Jahr \\ Vollum Institute, Oregon Health and Science University, Portland, Oregon 97239
}

\begin{abstract}
Exocytosis of synaptic vesicles occurs not only at synaptic active zones but also at ectopic sites. Ectopic exocytosis provides a direct and rapid mechanism for neurons to communicate with glia that does not rely on transmitter spillover from the synaptic cleft. In the cerebellar cortex the processes of Bergmann glia cells encase synapses between presynaptic climbing fiber varicosities and postsynaptic Purkinje cell spines and express both AMPA receptors and electrogenic glutamate transporters. AMPA receptors expressed by Purkinje cells and Bergmann glia cells are activated predominantly by synaptic and ectopic release, respectively, and therefore can be used to compare the properties of the two release mechanisms. We report that vesicular release differs at synaptic and ectopic sites in the magnitude of short-term plasticity and the proportions of $\mathrm{Ca}^{2+}$ channel subtypes that trigger glutamate release. High-affinity glutamate transporter-mediated currents in Bergmann glia cells follow the rules of synaptic release more closely than the rules of ectopic release, indicating that the majority of glutamate is released from conventional synapses. On the other hand, ectopic release produces highconcentration glutamate transients at Bergmann glia cell membranes that are necessary to activate low-affinity AMPA receptors rapidly. Ectopic release may provide a geographical cue to guide Bergmann glia cell membranes to surround active synapses and ensure efficient uptake of glutamate that diffuses out of the synaptic cleft.
\end{abstract}

Key words: Bergmann glia; Purkinje cell; synaptic transmission; short-term plasticity; spillover; glutamate transporter

\section{Introduction}

Exocytosis of synaptic vesicles occurs not only at synaptic active zones but also at sites outside of the active zones, i.e., ectopic sites. Freeze-fracture studies of the neuromuscular junction (Ceccarelli et al., 1979, 1988; Grohovaz et al., 1989), FM1-43 imaging studies that use total internal reflection fluorescence microscopy of retinal bipolar cells (Zenisek et al., 2000, 2003), and ultrastructural studies of hair cells (Beutner et al., 2001; Lenzi et al., 2002) all support the existence of ectopic release. How ectopic release is controlled and regulated remains primarily unknown. We have shown previously that ectopic release from cerebellar climbing fibers (CFs) and parallel fibers (PFs) can be detected by Bergmann glia cells (BGs) (Matsui and Jahr, 2003) that encase CF and PF synapses on Purkinje cells (PCs) (Palay and Chan-Palay, 1974; Spacek, 1985; Xu-Friedman et al., 2001; Grosche et al., 2002). AMPA receptors (AMPARs) and glutamate transporters expressed by PCs and BGs are activated differentially by glutamate released from synaptic and ectopic sites because of both their 10to $\sim 100$-fold different affinities for glutamate and their distinct locations. Because of this, they can be used to compare the properties of synaptic and ectopic release.

Received July 2, 2004; revised Aug. 23, 2004; accepted Aug. 31, 2004.

This work was supported by the Research Fellowship of the Uehara Memorial Foundation (to K.M.), Human Frontiers Science Program (Grant RG119/2000 to C.E.J.), and National Institutes of Health (Grant NS40056 to C.E.J.). We thank John Harrison, Richard Piet, and Jacques Wadiche for valuable suggestions on these experiments and comments on this manuscript.

Correspondence should be addressed to Craig E. Jahr, Vollum Institute, Oregon Health and Science University, L474, 3181 Southwest Sam Jackson Park Road, Portland, OR 97239. E-mail: jahr@ohsu.edu.

DOI:10.1523/JNEUROSCI.2650-04.2004

Copyright $\odot 2004$ Society for Neuroscience $\quad 0270-6474 / 04 / 248932-08 \$ 15.00 / 0$
Ectopic release may be particularly important for the maintenance of $\mathrm{BG}$ processes that surround $\mathrm{CF} \rightarrow \mathrm{PC}$ synapses. AMPARs expressed by BGs are $\mathrm{Ca}^{2+}$-permeable (Burnashev et al., 1992) because they lack the glutamate receptor 2 (GluR2) subunit. The introduction of GluR2 to BGs by viral delivery causes BG processes to retract from the synapse (Iino et al., 2001). Therefore, it is likely that the $\mathrm{Ca}^{2+}$-permeable AMPARs are necessary to maintain glial encasement of active synapses. However, AMPARs have a low affinity for glutamate $\left(\mathrm{EC}_{50}=1.2\right.$ to $\sim 1.8$ mM) (Bergles et al., 1997; Dzubay and Jahr, 1999) and are not particularly well suited for the detection of low concentrations of glutamate that diffuse from the synaptic cleft (but see Nielsen et al., 2004). Exocytosis directly across the extracellular space from the BG membrane more readily activates these low-affinity receptors (Matsui and Jahr, 2003). The determination of the mechanism and regulation of ectopic release is therefore important for understanding neural-glial communication.

We report that synaptic and ectopic release differ in key attributes, including short-term plasticity and the source of $\mathrm{Ca}^{2+}$ influx for triggering release. These differences in release mechanisms provide evidence for the presence of separate release sites governing synaptic transmission to neurons and glia. In contrast to AMPAR-mediated currents evoked in BGs, synaptically activated glutamate transporter currents (STCs) in BGs have properties closer to synaptic release than to ectopic release. It appears that high-affinity glutamate transporters expressed by BGs $\left(K_{\mathrm{m}}=\right.$ 10 to $\sim 100 \mu \mathrm{M}$ ) (Bergles et al., 1997; Danbolt, 2001) are well situated for detection and clearance of glutamate diffusing from the synaptic cleft. Thus the two glutamate receptors expressed by BGs have distinct roles: the low-affinity AMPARs detect ectopic 
release and promote encasement of active synapses, whereas high-affinity glutamate transporters take up glutamate released in the synaptic cleft as well as at ectopic sites and at least partially protect neighboring synapses from spillover.

\section{Materials and Methods}

Tissue preparation. Parasagittal $(250 \mu \mathrm{m})$ or coronal $(350 \mu \mathrm{m})$ cerebellar slices from postnatal day 12-15 (P12-P15) rats were used for the studies of CF-evoked and PF-evoked responses, respectively. Animals were anesthetized by inhalation of halothane and were decapitated, as approved by the Oregon Health and Science University Institutional Animal Care and Use Committee. Cerebella were cut with a vibroslicer (Leica Instruments, Nussloch, Germany) in ice-cold solution containing (in mM) $119 \mathrm{NaCl}$, $2.5 \mathrm{KCl}, 2 \mathrm{CaCl}_{2}, 1.3 \mathrm{MgCl}_{2}, 1 \mathrm{NaH}_{2} \mathrm{PO}_{4}, 26.2 \mathrm{NaHCO}_{3}$, and 11 glucose (saturated with $95 \% \mathrm{O}_{2} / 5 \% \mathrm{CO}_{2}$ ). The slices were incubated in the same solution at $34^{\circ} \mathrm{C}$ for $30 \mathrm{~min}$ and then stored at room temperature. During the recording the slices were superfused with the above solution with the addition of $100 \mu \mathrm{M}$ picrotoxin to block $\mathrm{GABA}_{\mathrm{A}}$ receptors. All recordings were performed at $32-35^{\circ} \mathrm{C}$, attained by using an in-line heating device (Warner Instruments, Hamden, CT).

Electrophysiological recording. Slices were visualized by using a $40 \times$ water immersion objective on an Axioskop 2 FS upright microscope (Zeiss, Thornwood, NY) equipped with infrared differential interference contrast. Whole-cell recordings were made with a MultiClamp 700A patch-clamp amplifier (Axon Instruments, Union City, CA). Signals were filtered at $2-4 \mathrm{kHz}$ and digitized at $10-50 \mathrm{kHz}$ with an ITC-18 interface (Instrutech, Port Washington, NY), using acquisition software written by J. S. Diamond in IgorPro software (WaveMetrics, Lake Oswego, OR). Pipettes with resistances of $1-2$ or 2-3 $M \Omega$ were used for recordings from PCs and BGs, respectively. Series resistance was compensated by $\sim 80 \%$ for the $\mathrm{PC}$ recordings, but not for the BG recordings. PCs typically were voltage clamped at -10 to $-30 \mathrm{mV}$ and BGs at $-65 \mathrm{mV}$. CFs were stimulated in parasagittal slices with a theta glass pipette filled with bath solution placed in the granule cell layer, using a constant voltage isolated stimulator $(20-100 \mu \mathrm{sec}$ pulse of $10-99 \mathrm{mV}$; Digitimer, Hertfordshire, UK). The pipette position and stimulus intensity were adjusted until the voltage necessary to produce an all-or-none response was minimized. PFs were stimulated in coronal slices with the stimulating electrode placed in the molecular layer $\sim 100 \mu \mathrm{m}$ from the recorded cell. Data analysis was performed with Axograph 4.6 (Axon Instruments), and statistical analysis was performed with Microsoft Excel (Redmond, WA) and StatView (SAS Institute, Cary, NC). Reported values are given as the mean \pm SD.

Pipette solutions and drugs. Pipette solutions for PC recordings contained (in mm) $35 \mathrm{CsF}, 100 \mathrm{CsCl}, 10 \mathrm{HEPES}$, and 10 EGTA. Pipette solutions for BG recordings contained $82 \mathrm{CsCH}_{3} \mathrm{SO}_{3}, 40 \mathrm{CsCl}, 20$ HEPES, 10 HEDTA, and $3 \mathrm{BaCl}_{2}\left(\mathrm{Ba}^{2+}\right.$ was included to increase input resistance of BG) (Matsui and Jahr, 2003). Both pipette solutions were titrated to $\mathrm{pH} 7.2$ with $\mathrm{CsOH}$. The sources of the chemicals are as follows: picrotoxin was from Sigma (St. Louis, MO); $(R, S)$ - $\alpha$-cyclopropyl4-phosphonophenylglycine (CPPG), cyclothiazide (CTZ), $\gamma$-Dglutamylglycine ( $\gamma$-D-GG), 2,3-dioxo-6-nitro-1,2,3,4- tetrahydrobenzo [f] quinoxaline-7-sulfonamide (NBQX), and DL-threo- $\beta$-benzyloxyaspartic acid (TBOA) were from Tocris Cookson (Ellisville, MO); $\omega$-agatoxin IVA was from Peptides International (Louisville, KY); $\omega$-conotoxin GVIA was from Bachem Biosciences (King of Prussia, PA). $\omega$-Agatoxin IVA and $\omega$-conotoxin GVIA were applied in the presence of $0.1 \mathrm{mg} / \mathrm{ml}$ cytochrome $c$ to block nonspecific binding sites.

\section{Results}

Short-term plasticity of synaptic versus ectopic release

CF stimulation causes multivesicular release at individual synapses on PCs, and this results in saturation of postsynaptic AMPARs (Wadiche and Jahr, 2001; Foster et al., 2002; Harrison and Jahr, 2003). Pairs of CF stimuli result in paired-pulse depression of the PC EPSC (Dittman and Regehr, 1998; Hashimoto and Kano, 1998; Silver et al., 1998), the magnitude of which is increased when AMPAR saturation is prevented by the rapidly dis-
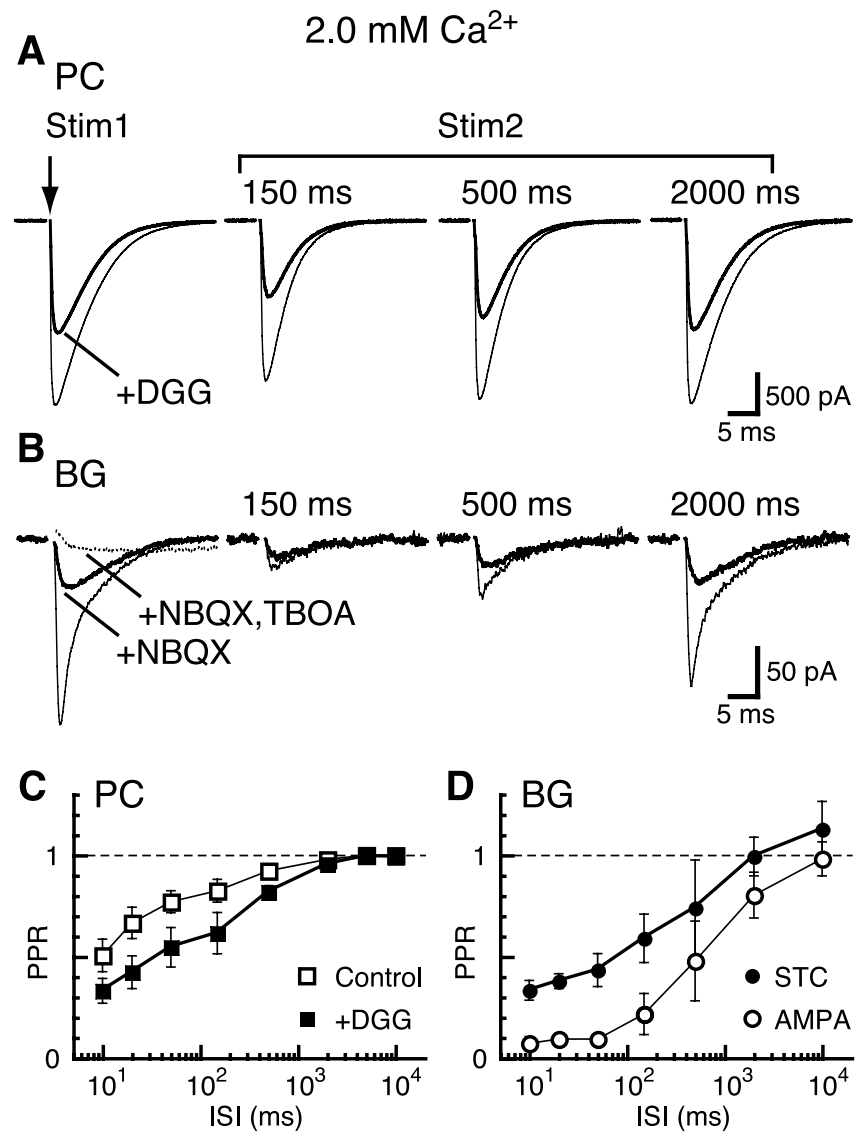

Figure 1. PPR recovery of CF-PC EPSCS and CF-BG responses in $2 \mathrm{~mm} \mathrm{Ca}^{2+}$. $A$, Shown are pairs of CF-PC EPSCs evoked at interstimulus intervals (ISIs) indicated at the top of the traces. Paired stimuli were separated by $15-25 \mathrm{sec}$. The application of $2 \mathrm{~mm} \gamma$-D-GG (thick line) decreased the amplitude of the first EPSC but reduced the second EPSC further, causing a decrease in the paired-pulse ratio (PPR = the amplitude of the second EPSC divided by the first EPSC). For ISIs shorter than $50 \mathrm{msec}$, the EPSCs overlapped. The second EPSC was isolated by subtracting the average of an unpaired $\mathrm{EPSC}\left(V h=-10 \mathrm{mV}\right.$ at $\left.32-35^{\circ} \mathrm{C}\right) . B$, Pairs of $\mathrm{CF}-\mathrm{BG}$ responses were evoked at the same ISls as above. NBQX (10 $\mu \mathrm{m}$ ) blocked AMPAR-mediated currents, isolating the STCS (thick line). Subtraction of the STCs from the control traces (thin line) yielded the AMPAR-mediated component of the evoked response. The STC could be abolished completely with the application of $50 \mu \mathrm{M} \mathrm{TBOA} \mathrm{(dotted} \mathrm{line).} \mathrm{Other} \mathrm{illustrated} \mathrm{records} \mathrm{are} \mathrm{the} \mathrm{result} \mathrm{of}$ subtracting traces recorded at the end of the experiment in NBQX and TBOA to reduce contamination by the stimulus artifact and the small but prolonged potassium component (Bergles and Jahr, 1997) (Vh $=-65 \mathrm{mV})$. C, PPR of CF-PC EPSCs plotted as a function of ISI for control and $\gamma$-D-GG conditions. Each data point represents the data in 3-17 cells. Note that the $x$-axis is in log scale. Error bars in this and all other figures indicate SD. D, PPR of CF-BG responses plotted as a function of ISI for the AMPAR-mediated current and STC component. Each data point represents the data in three to seven cells.

sociating competitive antagonist $\gamma$-D-GG (2 mM) (Fig. 1A) (Wadiche and Jahr, 2001; Foster et al., 2002). Because fewer vesicles are released at each synapse after the second stimulus than after the first, a smaller glutamate concentration transient results. Rapidly dissociating antagonists inhibit ligand binding resulting from smaller concentration transients more than from larger transients and therefore will alter the paired-pulse ratio (PPR = EPSC2/EPSC1) at synapses in which multivesicular release occurs (Tong and Jahr, 1994; Wadiche and Jahr, 2001; Foster et al., 2002). Because $\gamma$-D-GG prevents AMPAR saturation, the CF-PC EPSC follows changes in release more linearly in the presence of $\gamma$-D-GG than in its absence (Foster et al., 2002).

$\mathrm{BG}$ responses to CF stimulation consist of two components, a rapid AMPAR-mediated component and a slower glutamate transporter-mediated component; these components can be sep- 


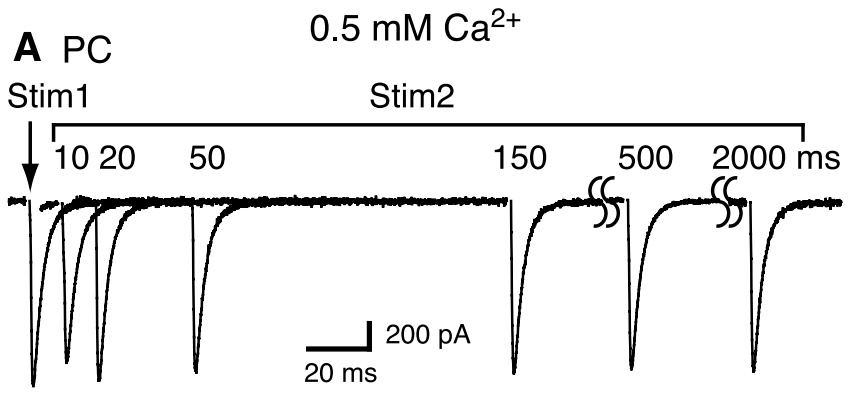

B BG
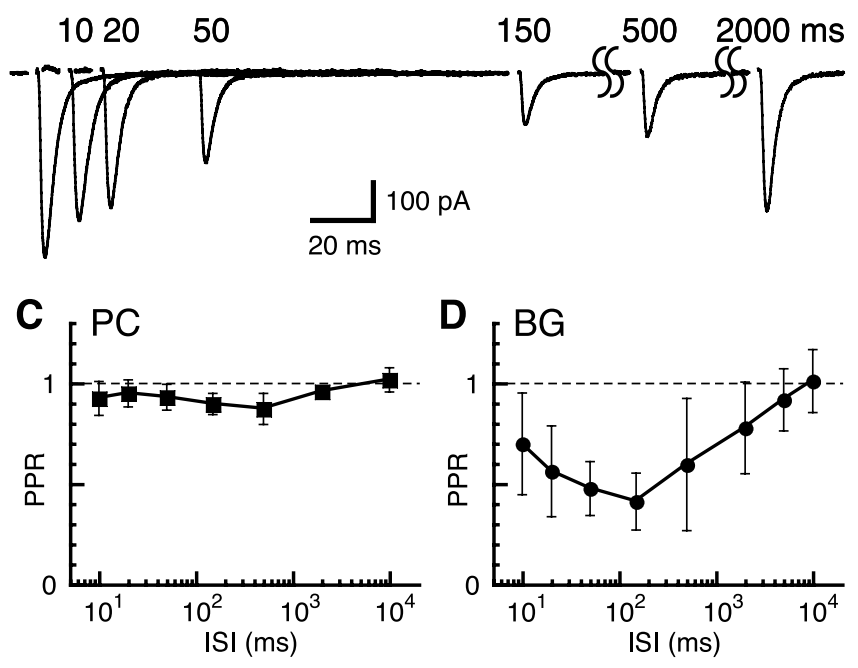

Figure 2. PPR recovery of CF-PC EPSCS and CF-BG responses in $0.5 \mathrm{~mm} \mathrm{Ca}^{2+} . A$, Pairedpulse responses of CF-PC EPSCs in $0.5 \mathrm{~mm} \mathrm{Ca}^{2+}$ and $2.8 \mathrm{~mm} \mathrm{Mg}^{2+}(\mathrm{Vh}=-10 \mathrm{mV})$. B, Pairedpulse responses of $\mathrm{CF}-\mathrm{BG}$ responses in $0.5 \mathrm{~mm} \mathrm{Ca}{ }^{2+}, 2.8 \mathrm{~mm} \mathrm{Mg}^{2+}$, and $200 \mu \mathrm{m} \mathrm{CTZ}(\mathrm{Vh}=$ $-65 \mathrm{mV}$ ). These responses are mediated predominantly by AMPARs, because there is very little contribution by the STC in this condition (Matsui and Jahr, 2003). C, PPR of CF-PC EPSCs plotted as a function of ISI ( $n=3-20$ cells). D, PPR of CF-BG responses plotted as a function of ISI ( $n=$ $4-35$ cells).

arated with the AMPAR antagonist NBQX (Fig. $1 B$ ) (Bergles et al., 1997; Dzubay and Jahr, 1999). As shown in Figure $1 B$, there was a remarkable decrease in the PPR of the BG AMPARmediated current, much larger than the PPR decrease of the CF-PC EPSC or the CF-BG STC, especially at short intervals (Fig. 1C,D). This large paired-pulse depression is not the result of desensitization because AMPARs recover much too rapidly to account for this depression (Raman and Trussell, 1995; Eliasof and Jahr, 1997; Wadiche and Jahr, 2001), and the depression is still seen in the presence of CTZ (Harrison and Jahr, 2003) (see below).

On the other hand, the PPR of the CF-BG STC was very similar to that of the CF-PC EPSC in the presence of $\gamma$-D-GG (Fig. 1C,D). This suggests that activation of the high-affinity BG glutamate transporters mainly reflects glutamate released from spillover of glutamate from the synaptic cleft (but see below), whereas activation of the low-affinity BG AMPARs predominantly reflects release from ectopic sites (Matsui and Jahr, 2003).

\section{Short-term plasticity in low $\mathrm{Ca}^{2+}$}

Paired-pulse depression of the CF-PC EPSC is almost eliminated when extracellular $\mathrm{Ca}^{2+}$ is lowered to $0.5 \mathrm{~mm}$ (Fig. $2 \mathrm{~A}, C$ ). In addition, multivesicular release abates and CF synapses release at most a single vesicle per action potential (Wadiche and Jahr, 2001; Foster et al., 2002). In this condition of monovesicular

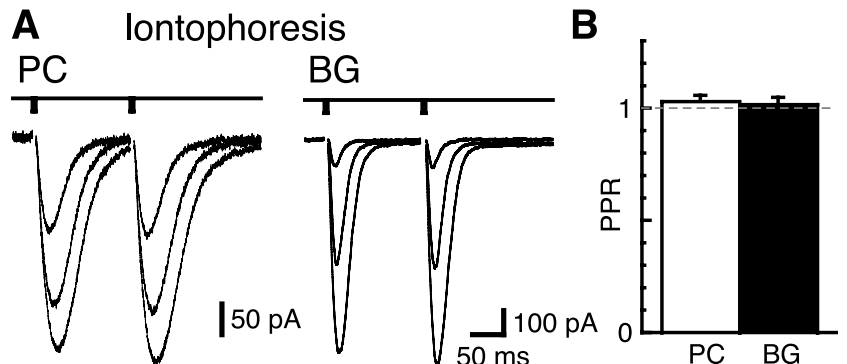

Figure 3. Responses of $\mathrm{PC}$ s and $\mathrm{BGs}$ to iontophoresis of glutamate. $A$, Responses of a $\mathrm{PC}$ and a $B G$ to paired iontophoretic pulses ( $5 \mathrm{msec},-5$ to approximately $-50 \mathrm{nA}$, with the braking current of +1.2 to approximately $+1.7 \mathrm{nA} ; 200$ to $\sim 400 \mathrm{M} \Omega$ iontophoretic electrode) of glutamate $(1 \mathrm{M}, \mathrm{pH} 8.0)$ at an ISI of $150 \mathrm{msec}(\mathrm{PC}, V h=-10 \mathrm{mV} ; \mathrm{BG}, V h=-65 \mathrm{mV})$. Extracellular solution contained $0.5 \mathrm{~mm} \mathrm{Ca}^{2+}, 2.8 \mathrm{~mm} \mathrm{Mg}^{2+}$, and $200 \mu \mathrm{M}$ CTZ to match the condition of Figure 2. The iontophoresis electrodes were placed in the molecular layer at locations that produced large responses. Currents were blocked with $10 \mu \mathrm{m}$ NBQX in both cell types (data not shown). In the illustrated recordings, three intensities of pulses were applied for each cell. $B$, Summary of the PPR of the responses to iontophoresis pulses. The open bar represents the average $\operatorname{PCPPR}(n=4)$, and the filled bar represents the average BG PPR $(n=5)$. A very small amount of facilitation was observed in both cells, which suggests that a small amount of "tipwarming effect" occurs at the iontophoresis electrode tip, causing a slightly larger amount of glutamate to be released on the second pulse.

release, BG AMPARs are activated predominantly, if not exclusively, by ectopic release; thus the CF-BG AMPAR-mediated current can be used to monitor changes in ectopic release in the absence of spillover from the synaptic active zones (Matsui and Jahr, 2003).

In contrast to the lack of short-term plasticity of the CF-PC EPSC in $0.5 \mathrm{mM} \mathrm{Ca}^{2+}$, the CF-BG AMPAR response still depressed, but with a peculiar time course (Fig. $2 B, D$ ). At an interstimulus interval (ISI) of $10 \mathrm{msec}$, paired-pulse depression of the CF-BG AMPAR response depressed less than at longer intervals; maximum depression was achieved at $150 \mathrm{msec}$. At an ISI of 150 msec the depression was significantly larger than that of the CF-PC EPSC (PC PPR, $0.90 \pm 0.05, n=20$; BG PPR, $0.41 \pm 0.14$, $n=35$; unpaired $t$ test, $p<0.001)$ as well as that of the CF-BG AMPAR response at $10 \mathrm{msec}$ (BG PPR, $0.70 \pm 0.25, n=28$; paired $t$ test, $p<0.001)$. PPR recovered fully by $\sim 10 \mathrm{sec}$. These differences in PPR in BGs and PCs in 0.5 and $2 \mathrm{mM} \mathrm{Ca}^{2+}$ suggest that separate rules govern synaptic and ectopic release.

How is the biphasic PPR recovery curve of the CF-BG AMPAR response in $0.5 \mathrm{mM} \mathrm{Ca}^{2+}$ produced? It may be that, like the CF-PC EPSC, depression of presynaptic release is diminished greatly by low $\mathrm{Ca}^{2+}$ and that the relatively slow onset of depression is a postsynaptic phenomenon. AMPAR desensitization is not responsible, however, because CTZ $(200 \mu \mathrm{M})$ was present in the recordings, although this does not rule out some different type of activity-dependent downregulation of AMPAR responsiveness. Two pieces of evidence, however, suggest that a decreased postsynaptic sensitivity is not responsible. First, two iontophoretic pulses of glutamate applied $150 \mathrm{msec}$ apart resulted in identical responses in both BGs and PCs (Fig. 3). This suggests that AMPARs on the BG membrane are not downregulated by exposure to glutamate. However, because glutamate presented by exocytotic release will result in a different concentration transient than iontophoresis does, we turned to another excitatory pathway in the cerebellum, the PFs, which show paired-pulse facilitation (Atluri and Regehr, 1996) and release directly onto BGs (Matsui and Jahr, 2003). 

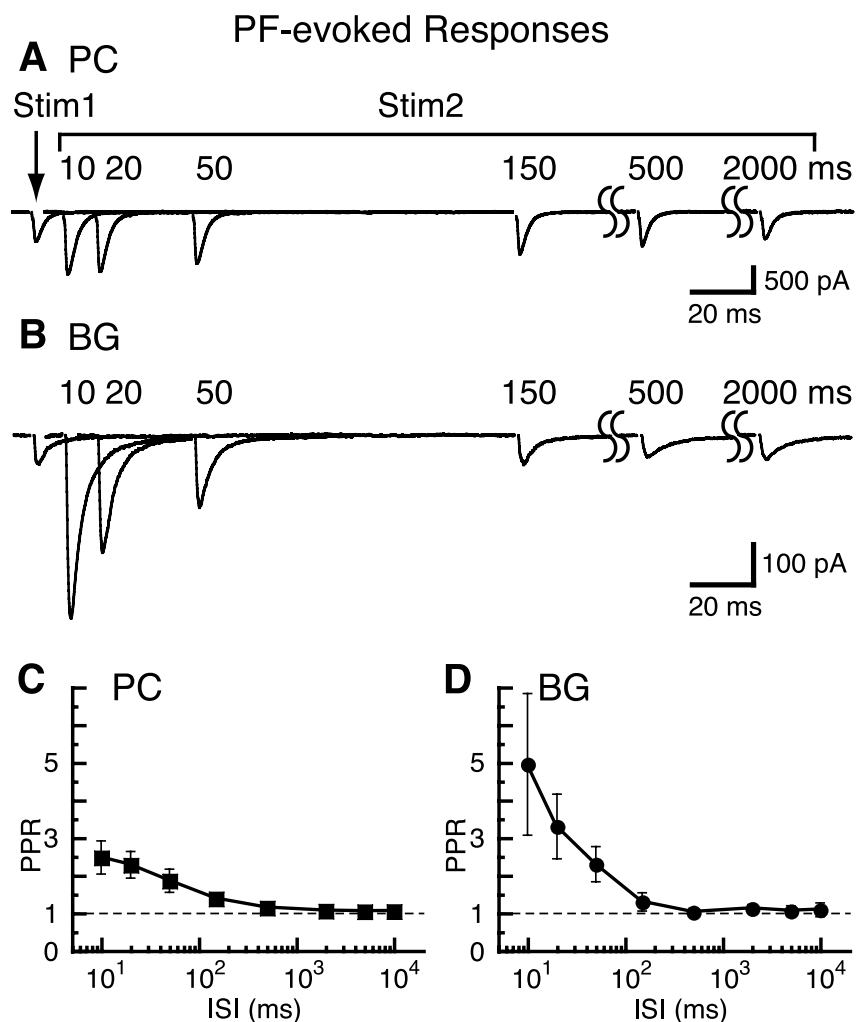

Figure 4. PPR recovery of PF-PCEPSCs and PF-BG responses. A, Paired PF-PCEPSC in $2 \mathrm{~mm}$ $\mathrm{Ca}^{2+}$ and $1.3 \mathrm{~mm} \mathrm{Mg}^{2+}(\mathrm{Vh}=-30 \mathrm{mV}) . B$, Paired PF-BG responses in $2 \mathrm{~mm} \mathrm{Ca}^{2+}, 1.3 \mathrm{~mm}$ $\mathrm{Mg}^{2+}$, and $200 \mu \mathrm{M}$ CTZ $(V h=-65 \mathrm{mV})$. PF-BG responses were recorded in the presence of CTZ to block desensitization, augment the AMPAR response, and minimize the proportion of the PF-BG current caused by glutamate transport (Dzubay and Jahr, 1999). Therefore, in the presence of $(T Z$, most of the $P F-B G$ response is mediated by AMPARs and could be blocked by $10 \mu \mathrm{m}$ NBQX (data not shown). C, PPR of PF-PC EPSCs versus ISI ( $n=3-5$ cells). D, PPR of PF-BG responses versus ISI ( $n=3-9$ cells).

\section{Short-term plasticity in PF-evoked responses}

PF stimulation evoked EPSCs in PCs that showed marked pairedpulse facilitation and had a maximum PPR value of $2.48 \pm 0.44$ $(n=5)$ at an ISI of $10 \mathrm{msec}$ in $2 \mathrm{mM} \mathrm{Ca}^{2+}$; this facilitation lasted for $\sim 150 \mathrm{msec}$ (Fig. 4A,C) (Atluri and Regehr, 1996). Facilitation of the PF-BG response had a similar time course but was remarkably larger; the PPR was $4.95 \pm 1.88(n=4)$ at an ISI of 10 msec (Fig. $4 B, D$ ) (unpaired $t$ test, $p<0.05$ ). Facilitation of the $\mathrm{PF}-\mathrm{BG}$ response, as well as the iontophoresis results, indicates that the depression seen with CF stimulation does not result from AMPAR downregulation. The different degree of paired-pulse facilitation in the PF-PC EPSC and the PF-BG response also suggests that $\mathrm{PC}$ and $\mathrm{BG}$ monitor glutamate release from different sites of PFs as well as CFs.

\section{Effects of transport blockade}

Glutamate transporters may alter the CF-BG AMPAR response PPR by buffering different proportions of the glutamate transient that follow the first and second stimulus (Harrison and Jahr, 2003) and thereby could contribute to the differences in PPRs recorded in PCs and BGs. The glutamate transporter blocker TBOA should eliminate this effect. However, in the presence of $0.5 \mathrm{mM} \mathrm{Ca}^{2+}$ and $200 \mu \mathrm{M} \mathrm{CTZ}$ the application of $30 \mu \mathrm{M} \mathrm{TBOA}$ caused an increase in the amplitudes of both CF-BG AMPAR responses but no change in PPR (Fig. $5 A, B$ ) (increase in first response, $1.70 \pm 0.36$ of control; PPR in control, $0.39 \pm 0.20$; $\mathrm{PPR}$ in TBOA, $0.41 \pm 0.18 ; n=4)$. The increase in both responses
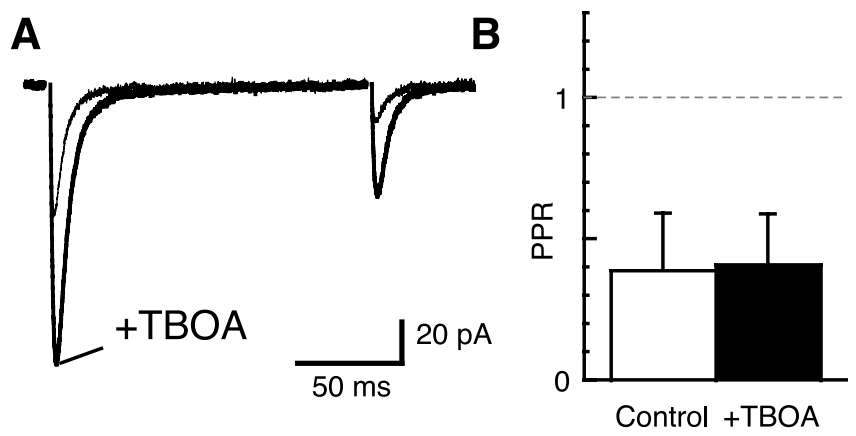

Figure 5. Glutamate transporters do not cause a large paired-pulse depression in $C F-B G$ responses. $A, C F-B G$ responses to paired-pulse stimuli with an $I S I$ of $150 \mathrm{msec}$ in $0.5 \mathrm{~mm} \mathrm{Ca}{ }^{2+}$, $2.8 \mathrm{~mm} \mathrm{Mg}^{2+}$, and $200 \mu \mathrm{M}$ CTZ ( $\left./ h=-65 \mathrm{mV}\right)$. The application of $30 \mu \mathrm{m}$ TBOA (thick line) increased both the first and the second response but had no effect on the PPR. $B$, Summary of the PPR of CF-BG response before (open bar) and after the application of TBOA (filled bar; $n=4$ ).

indicates that the BG AMPARs are protected somewhat by glutamate transporters that can compete with AMPARs for released glutamate. However, because TBOA increased both CF-BG AMPAR responses to a similar degree, the extent of shielding of the AMPARs by glutamate transporters is not different between the two stimuli in these conditions and therefore cannot account for the depression. In $2 \mathrm{mM} \mathrm{Ca}^{2+}$ and CTZ the shielding of BG AMPARs by glutamate transporters does affect the CF-BG AMPAR PPR (Harrison and Jahr, 2003). However, even after we inhibited the glutamate transporters with $30 \mu \mathrm{M}$ TBOA and blocked the mGluR-mediated presynaptic inhibition that is found in TBOA with $500 \mu \mathrm{M}$ CPPG (Harrison and Jahr, 2003), the CF-BG AMPAR PPR was still much smaller than the CF-PC EPSC PPR in $\gamma$-D-GG (at 150 msec ISI; PC PPR, $0.71 \pm 0.02, n=$ 4; BG PPR, $0.29 \pm 0.11, n=8$; unpaired $t$ test, $p<0.001$ ).

\section{Paired recordings from $\mathrm{PC}$ and $\mathrm{BG}$}

Because postsynaptic mechanisms apparently cannot account for the different degrees of paired-pulse depression seen in PCs and $\mathrm{BGs}$, presynaptic mechanisms were investigated. In the preceding recordings from $\mathrm{PCs}$ and $\mathrm{BGs}$ the membrane potential of the closely associated PC was not controlled; therefore, the PC likely fired complex spikes after CF stimulation. However, in voltageclamp recordings of PCs the membrane potential was held constant at -10 to approximately $-30 \mathrm{mV}$. If complex spikes cause the release of a substance that affects presynaptic release properties (e.g., cannabinoids or glutamate) (Kreitzer and Regehr, 2001; Duguid and Smart, 2004), this could account for the different PPRs in the two cells. We tested this possibility by recording simultaneously from pairs of PCs and BGs that share the same CF.

Cells in which responses to CF stimulation succeed or fail coincidentally were considered to share input from the same CF (Fig. 6A). In $2 \mathrm{mM} \mathrm{Ca}^{2+}$ the difference in PPRs in the two cell types was maintained despite the voltage-clamped PC (Fig. 6A). Similarly, when the solution was changed to $0.5 \mathrm{mM} \mathrm{Ca}^{2+}$ and $200 \mu \mathrm{M} \mathrm{CTZ}$, the difference in PPRs of the two cells remained (Fig. $6 B, C$ ) (PC PPR, $0.83 \pm 0.06$; BG PPR, $0.35 \pm 0.11 ; n=7$ cell pairs; paired $t$ test, $p<0.001)$ as found in individual recordings (Fig. 2). This confirms that synaptic and ectopic release have different degrees of short-term plasticity that is not caused by retrograde transmission from PCs. 


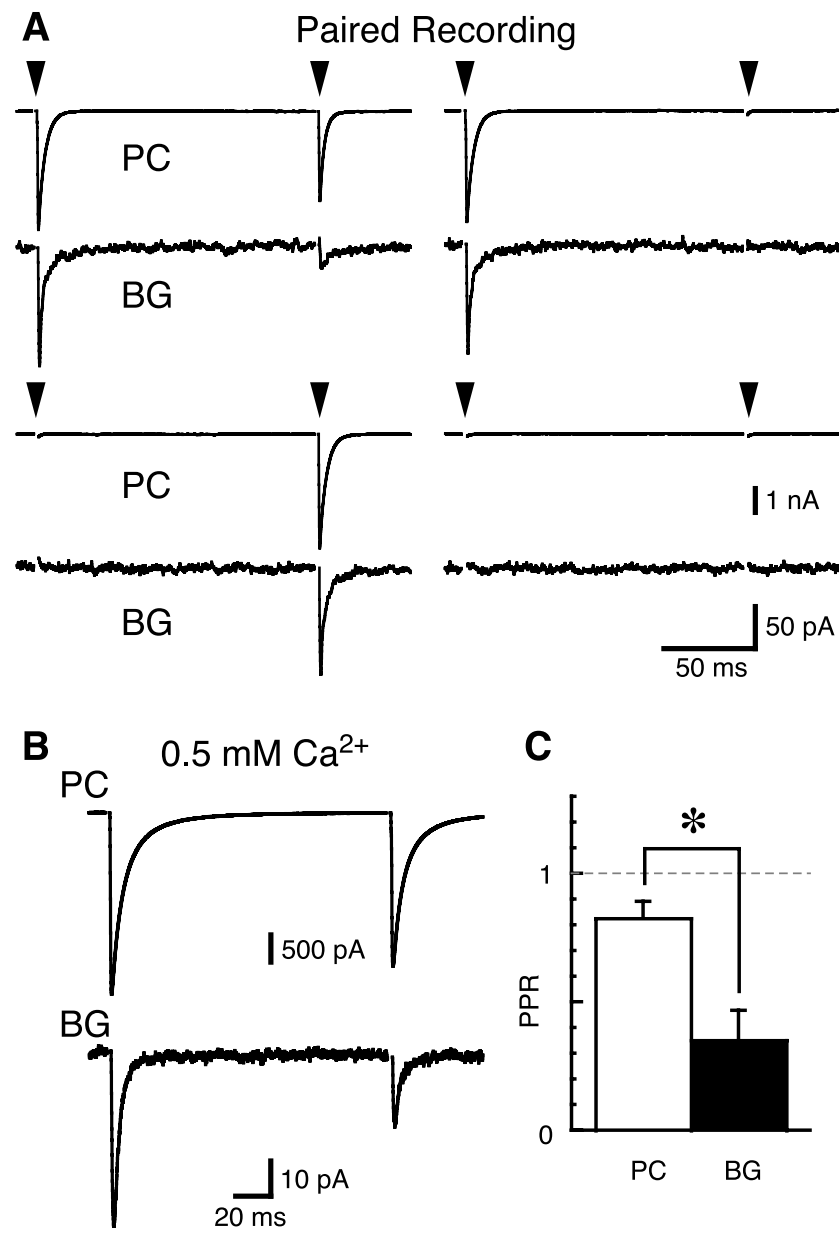

Figure 6. $\mathrm{PPR}$ difference between $\mathrm{PC}$ and $\mathrm{BG}$ s persists in paired recordings. $A$, Paired recording from a $P C(V h=-10 \mathrm{mV})$ and a $B G(V h=-65 \mathrm{mV})$ in $2 \mathrm{~mm} \mathrm{Ca}^{2+}, 1.3 \mathrm{~mm} \mathrm{Mg}^{2+}$, and no CTZ. Paired stimuli (timing shown by arrowheads) were given at an interval of $150 \mathrm{msec}$; stimulus strength was set near threshold so that some failures of CF stimulation occurred. The CF-evoked responses either succeeded or failed at the same time in the two cells, indicating that the two cells share the same CF. $B$, Responses to paired-pulse stimulation from the same cells as in $A$, with the extracellular solution changed to $0.5 \mathrm{~mm} \mathrm{Ca}^{2+}, 2.8 \mathrm{~mm} \mathrm{Mg}^{2+}$, and $200 \mu \mathrm{M}$ CTZ. Notice that the PPR difference in the two cells persists at this condition. C, Summary of the PPR at an ISI of 150 msec in paired recordings in the same condition as in $B$. Open bar is for CF-PC EPSC, and filled bar is for CF-BG responses ( $n=7$ cell pairs; paired $t$ test, ${ }^{*} p<0.001$ ).

Subtype of $\mathrm{Ca}^{2+}$ channel responsible for synaptic and ectopic release

The different amplitudes of paired-pulse depression of synaptic and ectopic release as monitored by PCs and BGs could reflect a dependence on different proportions of $\mathrm{Ca}^{2+}$ channel subtypes. At both the CF $\rightarrow$ PC synapse (Regehr and Mintz, 1994) and the calyx of Held (Wu et al., 1999) P/Q-type $\mathrm{Ca}^{2+}$ channels are coupled more strongly to release than are N-type $\mathrm{Ca}^{2+}$ channels. In addition, P/Q-type channels are concentrated at active zones, whereas $\mathrm{N}$-type channels are distributed more evenly throughout the calyx of Held (Wu et al., 1999). If $\mathrm{Ca}^{2+}$ channel subtypes are distributed similarly in the $\mathrm{CF}$ terminal, $\mathrm{N}$-type $\mathrm{Ca}^{2+}$ channels may have a larger role in triggering ectopic release than synaptic release.

CF-evoked synaptic and ectopic release were monitored in PC and $\mathrm{BG}$ recordings, respectively, in $0.5 \mathrm{mM} \mathrm{Ca}^{2+}$. Application of the P/Q-type $\mathrm{Ca}^{2+}$ channel-specific blocker $\omega$-agatoxin IVA (200 nM) (Mintz et al., 1992) in large part inhibited the responses in both PCs and BGs (Fig. $7 A, B)(P C, 0.17 \pm 0.08$ of control, $n=5$;
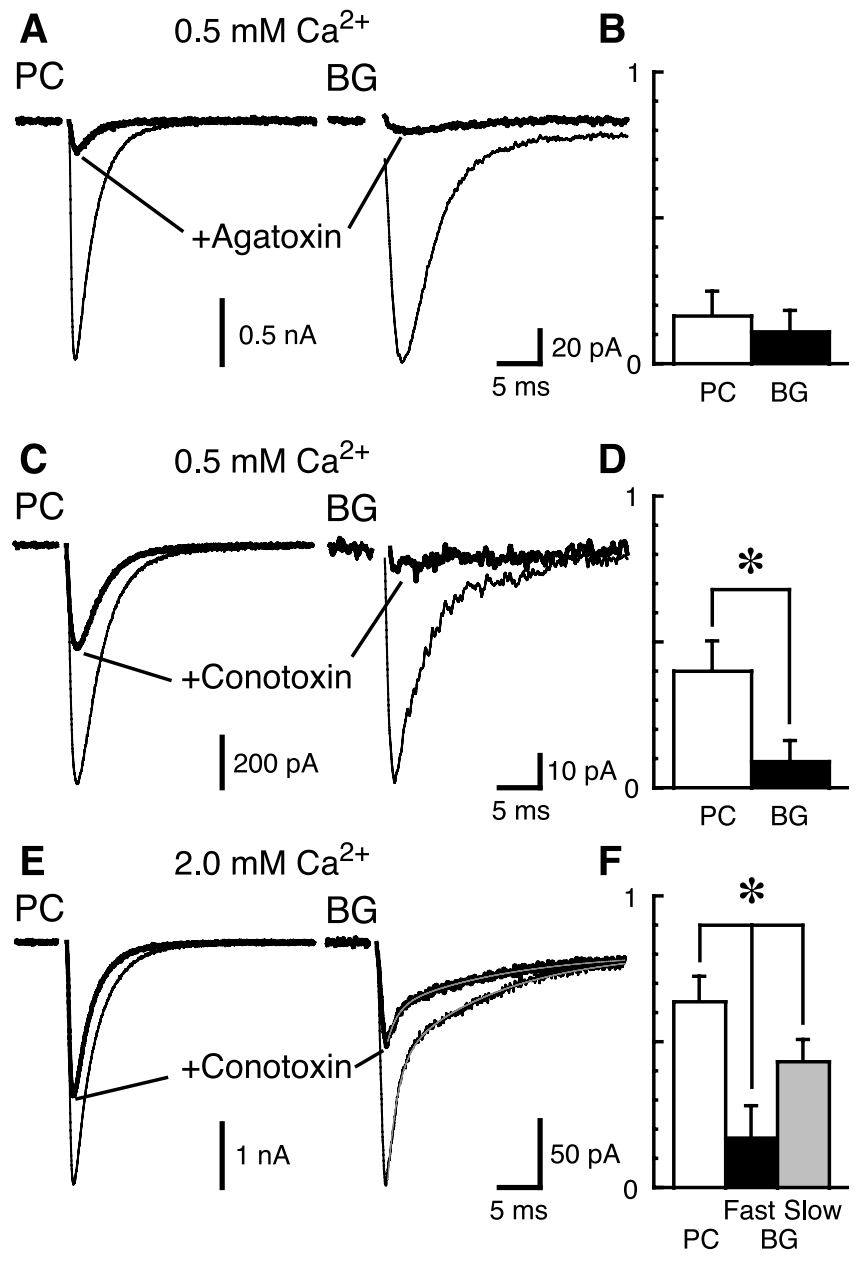

Figure 7. CF-PC EPSCS and CF-BG responses are affected differentially by subtype-specific $\mathrm{Ca}^{2+}$ channel blockers. A, CF-PC EPSCs were recorded in $0.5 \mathrm{~mm} \mathrm{Ca}{ }^{2+}$ and $2.8 \mathrm{~mm} \mathrm{Mg}^{2+}$ $(V h=-10 \mathrm{mV})$, and $(F-B G$ responses were recorded in the same divalents with $200 \mu \mathrm{M}$ CTZ $(V h=-65 \mathrm{mV})$ in the absence and presence of the P/Q-type $\mathrm{Ca}^{2+}$ channel blocker $\omega$-agatoxin IVA (200 nm). B, Summary of the ratio of the response amplitudes in the presence and absence of $\omega$-agatoxin IVA in A. CF-PC EPSC $(n=5)$; CF-BG response $(n=5)$. C, CF-PC EPSCs and CF-BG responses were recorded in the same conditions as in $A$ in the absence and presence of the N-type $\mathrm{Ca}^{2+}$ channel blocker $\omega$-conotoxin GVIA $(1 \mu \mathrm{M}) . D$, Summary of the ratio of the response amplitude in the presence and absence of $\omega$-conotoxin GVIA in C.CF-PCEPSC $(n=4)$; CF-BG response $(n=4)$; unpaired $t$ test, ${ }^{*} p=0.002$. E, $\omega$-Conotoxin GVIA $(1 \mu \mathrm{M})$ partially blocked the CF-PC EPSC but mainly blocked the initial fast component of the CF-BG response, whereas the late slow component was blocked less (gray lines in BG recordings are double exponential fits). (CF-PC EPSCs were recorded in $2 \mathrm{~mm} \mathrm{Ca}^{2+}, 1.3 \mathrm{~mm} \mathrm{Mg}^{2+}$, and $2 \mathrm{~mm} \gamma-\mathrm{D}-\mathrm{GG}$ $(V h=-10 \mathrm{mV}) ;(\mathrm{CF}-\mathrm{BG}$ responses were recorded with the same divalents without $\gamma$-D-GG $(V h=-65 \mathrm{mV}) . F$, Summary of the ratio of response amplitudes in the presence and absence of $\omega$-conotoxin GVIA in E.CF-PCEPSC $(n=5)$; CF-BG response $(n=5)$; ANOVA and Fisher's PLSD post hoc test, significantly different for all combinations; ${ }^{*} p<0.004$.

BG, $0.11 \pm 0.07$ of control, $n=5$ ). However, the N-type $\mathrm{Ca}^{2+}$ channel-specific blocker $\omega$-conotoxin GVIA $(1 \mu \mathrm{M})$ (Fujita et al., $1993)$ only partially blocked the CF-PC EPSC $(0.40 \pm 0.10$ of control; $n=4)$, whereas it almost completely abolished the CF-BG response (0.09 \pm 0.07 of control; $n=4)$ (Fig. 7C,D). $\mathrm{N}$-type $\mathrm{Ca}^{2+}$ channels therefore have a larger role in triggering ectopic release than synaptic release.

How are the CF-evoked responses in PC and BG affected by $\omega$-conotoxin GVIA in more physiological conditions $(2 \mathrm{~mm}$ $\left.\mathrm{Ca}^{2+}\right)$ ? In the presence of $\gamma-\mathrm{D}-\mathrm{GG}$, to protect PC AMPARs from saturation, we reduced the CF-PC EPSC to $0.64 \pm 0.08$ of control by $\omega$-conotoxin GVIA $(n=5)$ (Fig. $7 E, F)$. The CF-BG response 
is composed of an AMPAR-mediated current and an STC in 2 $\mathrm{mM} \mathrm{Ca}^{2+}$. The contribution of each component was evaluated by fitting the decay of the response with two exponential time constants, with the amplitude of the fast and slow components corresponding to the AMPAR-mediated current and STC component, respectively $\left(\tau_{\text {fast }}=1.37 \pm 0.31 \mathrm{msec} ; \tau_{\text {slow }}=10.94 \pm 1.28\right.$ msec; $n=5$ ) (Matsui and Jahr, 2003). $\omega$-Conotoxin GVIA affected the two components differently. Although the AMPARmediated current was reduced to $0.17 \pm 0.11$ of control, the STC was reduced much less, to $0.43 \pm 0.07(n=5)$. We suggest that, even in normal levels of $\mathrm{Ca}^{2+}$, the CF-BG AMPAR component mainly reflects ectopic release. Because the reduction of the STC by $\omega$-conotoxin GVIA fell between that of the CF-PC EPSC and the CF-BG AMPAR response, we conclude that BG glutamate transporters take up glutamate released from both ectopic and synaptic sites.

\section{Discussion}

We find that the properties of synaptic transmission from CF to $\mathrm{PC}$ and $\mathrm{CF}$ to $\mathrm{BG}$ are significantly different. Compared with CF-PC EPSCs, CF-BG AMPAR responses exhibit larger pairedpulse depression and greater dependence on $\mathrm{Ca}^{2+}$ influx through $\mathrm{N}$-type $\mathrm{Ca}^{2+}$ channels. These differences indicate that PC and BG AMPARs detect glutamate released from different sources and support the idea that ectopic release mediates rapid transmission between neurons and glia in the cerebellum.

\section{Physiological relevance of highly depressing ectopic release} CF-BG AMPAR responses show dramatic paired-pulse depression, much larger than that of the CF-PC EPSC, indicating that ectopic release is not well suited for high-frequency transmission. However, the CF-BG response recovers fully in a few seconds and, because the in vivo firing rate of CFs is typically very low $(\sim 1$ $\mathrm{Hz}$ ) (Armstrong and Rawson, 1979; Ito, 1984), ectopic release will not be a rare event. Although inferior olivary neurons, which give rise to CFs, can fire action potentials at a frequency of $\sim 10$ $\mathrm{Hz}$ (Llinás and Yarom, 1986), such high-frequency firing likely occurs in short bursts in physiological conditions (Lang et al., 1999). High-frequency bursts may cause reliable transmission to BG only after the first action potential. This extreme form of depression essentially works as a steep low-pass filter for CF-BG transmission.

\section{Mechanism of depression of ectopic release}

What property of ectopic release makes the CF-BG AMPAR response depress so dramatically? In the case of conventional glutamatergic synaptic transmission, a low PPR generally is ascribed to high release probability, the depression resulting from the depletion of readily releasable synaptic vesicles by the first stimulus (Zucker and Regehr, 2002). However, in the case of CF-BG AMPAR responses, low PPR persists even when the extracellular $\mathrm{Ca}^{2+}$ is reduced to $0.5 \mathrm{~mm}$, similar to the case reported at inhibitory synapses (Galarreta and Hestrin, 1998; Kraushaar and Jonas, 2000; Kirischuk et al., 2002). In low $\mathrm{Ca}^{2+}$ the depression is less at very short intervals $(\sim 10 \mathrm{msec})$ than at longer intervals $(\sim 150 \mathrm{msec})$. This unique result suggests that not all of the vesicles are depleted with the first stimulus. One could imagine that, at short stimulus intervals, residual intracellular $\mathrm{Ca}^{2+}$ would allow $\mathrm{Ca}^{2+}$ entering from the second action potential to spread further from the source of $\mathrm{Ca}^{2+}$ influx, allowing vesicles at more distant sites to be exposed to concentrations of $\mathrm{Ca}^{2+}$ sufficient for ectopic release. This partial reversal of depression lasts $\sim 150$ msec, similar to the time course of facilitation at PF synapses that results from residual $\mathrm{Ca}^{2+}$ (Atluri and Regehr, 1996).

Alternatively, activity could regulate differentially the synaptic and ectopic release probability. For example, feedback by transmitters could be responsible for the differences in synaptic and ectopic PPRs. However, homosynaptic mGluR activation is not responsible for the depression because mGluR antagonists had no effect on the magnitude or the time course of recovery of CF-BG PPR (data not shown) (Harrison and Jahr, 2003), and a G-protein-coupled mechanism for depression seems unlikely because it starts as early as $\sim 10 \mathrm{msec}$, too fast for G-proteinmediated mechanisms (Hille, 2001). Endocannabinoidmediated suppression of release is similarly unlikely because its actions occur even more slowly (Kreitzer and Regehr, 2001; Maejima et al., 2001; Wilson and Nicoll, 2001). In addition, the paired voltage-clamp recordings of PCs and BGs would have disrupted most forms of retrograde signal from PC to CF terminals, yet the low PPR of CF-BG AMPAR responses remained.

Another intriguing possibility for the mechanism of suppression of release is the inactivation of $\mathrm{Ca}^{2+}$ channels (Hille, 2001). Presynaptic $\mathrm{Ca}^{2+}$ channels can inactivate rapidly enough to explain the onset of the depression and can persist for seconds (Dobrunz et al., 1997; Forsythe et al., 1998; Kirischuk et al., 2002). The reason that synaptic release and ectopic release behave differently could be either that the $\mathrm{Ca}^{2+}$ channels responsible for ectopic release are more prone to inactivation (N-type $\mathrm{Ca}^{2+}$ channels inactivate more readily than the P/Q-type) (Patil et al., 1998 ) or that release machinery for ectopic release is more sensitive to small changes in $\mathrm{Ca}^{2+}$ influx (Harrison and Jahr, 2003) or both. Fluorometric $\mathrm{Ca}^{2+}$ measurements of $\mathrm{CF}$ have shown that action potential-induced presynaptic $\mathrm{Ca}^{2+}$ transients do not show paired-pulse depression (Kreitzer et al., 2000). However, it is possible that the decreased $\mathrm{Ca}^{2+}$ influx resulting from inactivation of $\mathrm{N}$-type $\mathrm{Ca}^{2+}$ channels is immeasurable in the context of bulk intracellular $\mathrm{Ca}^{2+}$. Selective adaptation of the $\mathrm{Ca}^{2+}$ sensor for ectopic vesicles also could account for the depression (Chapman et al., 1995; Hsu et al., 1996).

\section{Dependence of ectopic release on $\mathrm{Ca}^{2+}$ influx}

The CF-BG AMPAR response is more sensitive to the inhibition of $\mathrm{Ca}^{2+}$ influx than the CF-PC EPSC (Harrison and Jahr, 2003). In addition, increasing internal $\mathrm{Ca}^{2+}$ buffering by the application of EGTA-AM suppressed CF-BG AMPAR responses more dramatically than in the CF-PC EPSCs (Matsui and Jahr, 2003). In the current study we have shown that $\mathrm{N}$-type $\mathrm{Ca}^{2+}$ channels play a larger role in triggering glutamate release at ectopic sites than at synaptic sites. If $\mathrm{P} / \mathrm{Q}$-type $\mathrm{Ca}^{2+}$ channels are concentrated in the synaptic active zone and $\mathrm{N}$-type $\mathrm{Ca}^{2+}$ channels are distributed throughout the presynaptic terminal, as has been shown at the calyx of Held synapse (Wu et al., 1999), this could explain the larger role of $\mathrm{N}$-type $\mathrm{Ca}^{2+}$ channels in mediating ectopic release. However, P/Q-type $\mathrm{Ca}^{2+}$ channel blockers also suppressed $\mathrm{CF}-\mathrm{BG}$ responses nearly completely, indicating that $\mathrm{Ca}^{2+}$ influx triggering ectopic release is not solely through the peripheral $\mathrm{N}$-type $\mathrm{Ca}^{2+}$ channels. Because ectopic release is also more sensitive to increases in $\mathrm{Ca}^{2+}$ buffering, it is possible that the distance between the $\mathrm{Ca}^{2+}$ channels and vesicles is not coupled as tightly as at the synaptic sites (Meinrenken et al., 2002). Whether the distance of ectopic fusion events from the $\mathrm{Ca}^{2+}$ channels, as well as the $\mathrm{Ca}^{2+}$ sensitivity of ectopic exocytosis machinery, differs from synaptic events remains to be determined. 


\section{Spillover depends on the detector}

The size of the PPR differed dramatically between the AMPAR response and STC component of the CF-BG responses. In addition, the degree of block of the two components by the N-type $\mathrm{Ca}^{2+}$ channel blocker $\omega$-conotoxin GVIA is different. These differences arise from the disparate affinities of the two glutamate receptors and thus their ability to detect extracellular glutamate. Low-affinity AMPARs readily detect rapid and high concentration transients of glutamate, making them suitable for detecting local ectopic release. The affinity of glutamate transporters is 10 to 100 times higher than that of AMPARs (Bergles et al., 1997; Danbolt, 2001), allowing them to detect lower glutamate transients as well. Whether glutamate spillover is significant depends on the type of detectors that are present as well as their distance from the site of release. The lower sensitivity of the CF-BG STC to $\omega$-conotoxin GVIA, as well as its PPR, suggests that vesicular release from both ectopic and synaptic sites activates BG glutamate transporters and that release from synaptic sites exceeds that from ectopic sites.

BG AMPAR activation by CF stimulation is rapid and terminates with a time constant of 1 to $\sim 2 \mathrm{msec}$ in the absence of CTZ. These $\mathrm{Ca}^{2+}$-permeable AMPARs have rapid kinetics (Bergles et al., 1997; Dzubay and Jahr, 1999) that, in aspiny dendrites of neocortical fast-spiking interneurons, results in highly localized $\mathrm{Ca}^{2+}$ signals (Goldberg et al., 2003). Because $\mathrm{Ca}^{2+}$ influx via BG AMPARs is required for the maintenance of glial wrapping of the $\mathrm{CF} \rightarrow$ PC synapse (Iino et al., 2001), it is likely that localized $\mathrm{Ca}^{2+}$ increases in BG (Grosche et al., 1999) provide geographical cues as to where the active synapses are located. In addition to the rapid kinetics of the AMPAR, exocytosis directly across the extracellular space from the BG membrane also is required for localized $\mathrm{Ca}^{2+}$ increases. Low concentration and prolonged glutamate transients resulting from spillover, coupled with highaffinity slowly activating receptors such as mGluRs, would allow less precise signaling in both time and space. Because a blockade of glutamate transporters increased the peak amplitude of CF-BG AMPAR responses, AMPARs and glutamate transporters likely are expressed near each other, possibly intermingling, and compete for extracellular glutamate (Tong and Jahr, 1994; Diamond and Jahr, 1997). This arrangement additionally may tune the localization and timing of BG AMPAR activation and the subsequent $\mathrm{Ca}^{2+}$ rise. Whether such temporal and spatial resolution occurs will require $\mathrm{Ca}^{2+}$ imaging from the fine processes of BG.

\section{References}

Armstrong DM, Rawson JA (1979) Activity patterns of cerebellar cortical neurones and climbing fibre afferents in the awake cat. J Physiol (Lond) 289:425-448.

Atluri PP, Regehr WG (1996) Determinants of the time course of facilitation at the granule cell $\rightarrow$ Purkinje cell synapse. J Neurosci 16:5661-5671.

Bergles DE, Jahr CE (1997) Synaptic activation of glutamate transporters in hippocampal astrocytes. Neuron 19:1297-1308.

Bergles DE, Dzubay JA, Jahr CE (1997) Glutamate transporter currents in Bergmann glial cells follow the time course of extrasynaptic glutamate. Proc Natl Acad Sci USA 94:14821-14825.

Beutner D, Voets T, Neher E, Moser T (2001) Calcium dependence of exocytosis and endocytosis at the cochlear inner hair cell afferent synapse. Neuron 29:681-690.

Burnashev N, Khodorova A, Jonas P, Helm PJ, Wisden W, Monyer H, Seeburg PH, Sakmann B (1992) Calcium-permeable AMPA-kainate receptors in fusiform cerebellar glial cells. Science 256:1566-1570.

Ceccarelli B, Grohovaz F, Hurlbut WP (1979) Freeze-fracture studies of frog neuromuscular junctions during intense release of neurotransmitter. II. Effects of electrical stimulation and high potassium. J Cell Biol 81:178-192.
Ceccarelli B, Fesce R, Grohovaz F, Haimann C (1988) The effect of potassium on exocytosis of transmitter at the frog neuromuscular junction. J Physiol (Lond) 401:163-183.

Chapman ER, Hanson PI, An S, Jahn R (1995) $\mathrm{Ca}^{2+}$ regulates the interaction between synaptotagmin and syntaxin 1 . J Biol Chem 270:23667-23671.

Danbolt NC (2001) Glutamate uptake. Prog Neurobiol 65:1-105.

Diamond JS, Jahr CE (1997) Transporters buffer synaptically released glutamate on a submillisecond time scale. J Neurosci 17:4672-4687.

Dittman JS, Regehr WG (1998) Calcium dependence and recovery kinetics of presynaptic depression at the climbing fiber $\rightarrow$ Purkinje cell synapse. J Neurosci 18:6147-6162.

Dobrunz LE, Huang EP, Stevens CF (1997) Very short-term plasticity in hippocampal synapses. Proc Natl Acad Sci USA 94:14843-14847.

Duguid IC, Smart TG (2004) Retrograde activation of presynaptic NMDA receptors enhances GABA release at cerebellar interneuron-Purkinje cell synapses. Nat Neurosci 7:525-533.

Dzubay JA, Jahr CE (1999) The concentration of synaptically released glutamate outside of the climbing fiber-Purkinje cell synaptic cleft. J Neurosci 19:5265-5274.

Eliasof S, Jahr CE (1997) Rapid AMPA receptor desensitization in catfish cone horizontal cells. Vis Neurosci 14:13-18.

Forsythe ID, Tsujimoto T, Barnes-Davies M, Cuttle MF, Takahashi T (1998) Inactivation of presynaptic calcium current contributes to synaptic depression at a fast central synapse. Neuron 20:797-807.

Foster KA, Kreitzer AC, Regehr WG (2002) Interaction of postsynaptic receptor saturation with presynaptic mechanisms produces a reliable synapse. Neuron 36:1115-1126.

Fujita Y, Mynlieff M, Dirksen RT, Kim MS, Niidome T, Nakai J, Friedrich T, Iwabe N, Miyata T, Furuichi T, Furutama D, Mikoshiba K, Mori Y, Beam KG (1993) Primary structure and functional expression of the $\omega$-conotoxin-sensitive $\mathrm{N}$-type calcium channel from rabbit brain. Neuron 10:585-598.

Galarreta M, Hestrin S (1998) Frequency-dependent synaptic depression and the balance of excitation and inhibition in the neocortex. Nat Neurosci 1:587-594.

Goldberg JH, Tamas G, Aronov D, Yuste R (2003) Calcium microdomains in aspiny dendrites. Neuron 40:807-821.

Grohovaz F, Fesce R, Haimann C (1989) Dual effect of potassium on transmitter exocytosis. Cell Biol Int Rep 13:1085-1095.

Grosche J, Matyash V, Moller T, Verkhratsky A, Reichenbach A, Kettenmann H (1999) Microdomains for neuron-glia interaction: parallel fiber signaling to Bergmann glial cells. Nat Neurosci 2:139-143.

Grosche J, Kettenmann H, Reichenbach A (2002) Bergmann glial cells form distinct morphological structures to interact with cerebellar neurons. J Neurosci Res 68:138-149.

Harrison J, Jahr CE (2003) Receptor occupancy limits synaptic depression at climbing fiber synapses. J Neurosci 23:377-383.

Hashimoto K, Kano M (1998) Presynaptic origin of paired-pulse depression at climbing fibre-Purkinje cell synapses in the rat cerebellum. J Physiol (Lond) 506:391-405.

Hille B (2001) Ionic channels of excitable membranes. Sunderland, MA: Sinauer.

Hsu SF, Augustine GJ, Jackson MB (1996) Adaptation of $\mathrm{Ca}^{2+}$-triggered exocytosis in presynaptic terminals. Neuron 17:501-512.

Iino M, Goto K, Kakegawa W, Okado H, Sudo M, Ishiuchi S, Miwa A, Takayasu Y, Saito I, Tsuzuki K, Ozawa S (2001) Glia-synapse interaction through $\mathrm{Ca}^{2+}$-permeable AMPA receptors in Bergmann glia. Science 292:926-929.

Ito M (1984) The cerebellum and neural control. New York: Raven.

Kirischuk S, Clements JD, Grantyn R (2002) Presynaptic and postsynaptic mechanisms underlie paired pulse depression at single GABAergic boutons in rat collicular cultures. J Physiol (Lond) 543:99-116.

Kraushaar U, Jonas P (2000) Efficacy and stability of quantal GABA release at a hippocampal interneuron $\rightarrow$ principal neuron synapse. J Neurosci 20:5594-5607.

Kreitzer AC, Regehr WG (2001) Retrograde inhibition of presynaptic calcium influx by endogenous cannabinoids at excitatory synapses onto Purkinje cells. Neuron 29:717-727.

Kreitzer AC, Gee KR, Archer EA, Regehr WG (2000) Monitoring presynaptic calcium dynamics in projection fibers by in vivo loading of a novel calcium indicator. Neuron 27:25-32. 
Lang EJ, Sugihara I, Welsh JP, Llinás R (1999) Patterns of spontaneous Purkinje cell complex spike activity in the awake rat. J Neurosci 19:2728-2739.

Lenzi D, Crum J, Ellisman MH, Roberts WM (2002) Depolarization redistributes synaptic membrane and creates a gradient of vesicles on the synaptic body at a ribbon synapse. Neuron 36:649-659.

Llinás R, Yarom Y (1986) Oscillatory properties of guinea-pig inferior olivary neurones and their pharmacological modulation: an in vitro study. J Physiol (Lond) 376:163-182.

Maejima T, Hashimoto K, Yoshida T, Aiba A, Kano M (2001) Presynaptic inhibition caused by retrograde signal from metabotropic glutamate to cannabinoid receptors. Neuron 31:463-475.

Matsui K, Jahr CE (2003) Ectopic release of synaptic vesicles. Neuron 40:1173-1183.

Meinrenken CJ, Borst JG, Sakmann B (2002) Calcium secretion coupling at calyx of Held governed by nonuniform channel-vesicle topography. J Neurosci 22:1648-1667.

Mintz IM, Venema VJ, Swiderek KM, Lee TD, Bean BP, Adams ME (1992) P-type calcium channels blocked by the spider toxin $\omega$-Aga-IVA. Nature 355:827-829.

Nielsen TA, DiGregorio DA, Silver RA (2004) Modulation of glutamate mobility reveals the mechanism underlying slow-rising AMPAR EPSCs and the diffusion coefficient in the synaptic cleft. Neuron 42:757-771.

Palay SL, Chan-Palay V (1974) Cerebellar cortex. New York: Springer.

Patil PG, Brody DL, Yue DT (1998) Preferential closed-state inactivation of neuronal calcium channels. Neuron 20:1027-1038.

Raman IM, Trussell LO (1995) The mechanism of $\alpha$-amino-3-hydroxy-5methyl-4-isoxazolepropionate receptor desensitization after removal of glutamate. Biophys J 68:137-146.
Regehr WG, Mintz IM (1994) Participation of multiple calcium channel types in transmission at single climbing fiber to Purkinje cell synapses. Neuron 12:605-613.

Silver RA, Momiyama A, Cull-Candy SG (1998) Locus of frequencydependent depression identified with multiple-probability fluctuation analysis at rat climbing fibre-Purkinje cell synapses. J Physiol (Lond) 510:881-902.

Spacek J (1985) Three-dimensional analysis of dendritic spines. III. Glial sheath. Anat Embryol (Berl) 171:245-252.

Tong G, Jahr CE (1994) Block of glutamate transporters potentiates postsynaptic excitation. Neuron 13:1195-1203.

Wadiche JI, Jahr CE (2001) Multivesicular release at climbing fiber-Purkinje cell synapses. Neuron 32:301-313.

Wilson RI, Nicoll RA (2001) Endogenous cannabinoids mediate retrograde signaling at hippocampal synapses. Nature 410:588-592.

Wu LG, Westenbroek RE, Borst JG, Catterall WA, Sakmann B (1999) Calcium channel types with distinct presynaptic localization couple differentially to transmitter release in single calyx-type synapses. J Neurosci 19:726-736.

Xu-Friedman MA, Harris KM, Regehr WG (2001) Three-dimensional comparison of ultrastructural characteristics at depressing and facilitating synapses onto cerebellar Purkinje cells. J Neurosci 21:6666-6672.

Zenisek D, Steyer JA, Almers W (2000) Transport, capture and exocytosis of single synaptic vesicles at active zones. Nature 406:849-854.

Zenisek D, Davila V, Wan L, Almers W (2003) Imaging calcium entry sites and ribbon structures in two presynaptic cells. J Neurosci 23:2538-2548.

Zucker RS, Regehr WG (2002) Short-term synaptic plasticity. Annu Rev Physiol 64:355-405. 